\title{
Padrões geográficos em diversidades de espécies
}

Evidências em profusão sugerem que as árvores da floresta tropical podem ser especializadas para certos solos e condições climáticas. Mas poderia a variabilidade no ambiente físico dos trópicos por ser responsável por uma diversidade de dez vezes (ou mais) maior de plantas nos trópicos do que em florestas temperadas? Parece improvável, a menos que as plantas reconheçam diferenças muito mais finas no ambiente dos trópicos do que das regiões temperadas.

Palavras-chave: Padrões geográficos; Diversidade de espécies; Floresta tropical; Hipótese da loteria.

\section{Geographical patterns in diversity of species}

Profound evidence suggests that rainforest trees may be specialized for certain soils and climatic conditions. But could variability in the physical environment of the tropics account for ten times (or more) greater diversity of plants in the tropics than in temperate forests? It seems unlikely, unless plants recognize much finer differences in the tropics than in temperate regions.

Keywords: Geographic patterns; Species diversity; Tropical forest; Lottery hypothesis

Topic: Notas Científicas

Reviewed anonymously in the process of blind peer.
Received: 09/09/2019

Approved: 11/01/2020
Gustavo Aveiro Lins (it

Universidade Federal Rural do Rio de Janeiro, Brasil

http://lattes.cnpq.br/5173989372426437

http://orcid.org/0000-0002-0244-6925

gustavoaveiro@gmail.com

Josimar Ribeiro de Almeida (iD

Universidade do Estado do Rio de Janeiro, Brasil

http://lattes.cnpq.br/3215586187698472

http://orcid.org/0000-0001-5993-0665

almeida@poli.ufri.br

Lais Alencar de Aguiar (iD)

Comissão Nacional de Energia Nuclear, Brasil

http://lattes.cnpq.br/5785500333245448

http://orcid.org/0000-0002-1551-4085

aguiar.lais@gmail.com
Tainá Pellegrino Martins

Universidade do Estado do Rio de Janeiro, Brasil

tainapellegrino@outlook.com
Referencing this:

LINS, G. A.; ALMEIDA, J. R.; AGUIAR, L. A.; MARTINS, T. P.. Padrões geográficos em diversidades de espécies. Agrariae Liber, v.2, n.1, p.69, 2020. DOI: http://doi.org/10.6008/CBPC2674-6476.2020.001.0002 


\section{INTRODUÇÃO}

Na maioria dos grandes grupos taxonômicos de organismos - vegetal, animal, protista e monera - o número de espécies aumenta marcantemente, com umas poucas exceções em direção ao equador. Por exemplo, numa região a 60ㅇ de latitude norte, poderíamos encontrar 10 espécies de formigas; a 40으, entre 50 e 100 espécies; e numa área similar a 20ㅇdo equador, entre 100 e 200 espécies. A Groenlândia é o lar de 56 espécies de pássaros procriadores; New York de 105; a Guatemala, de 269 e a Colômbia, de 1395. A diversidade nos ambientes marinhos segue uma tendência semelhante: as águas árticas abrigam 100 espécies de tunicados, mais de 400 espécies são conhecidas nas regiões temperadas e mais de 600 nos mares tropicais.

Dentro de uma dada faixa de latitude em volta do globo terrestre, o número de espécies pode variar muito entre os habitats de acordo com a produtividade, grau de heterogeneidade estrutural, a adequabilidade de condições físicas. Por exemplo, um censo de aves em pequenas áreas (usualmente de 5 a 20 hectares) de habitats relativamente uniformes revela cerca de 6 espécies de aves procriadoras em campos, 14 em habitats de arbustos e 24 em zonas de florestas decíduas inundáveis. A estrutura do habitat aparentemente sobrepuja a produtividade na determinação da diversidade das espécies. Os pântanos são produtivos, mas estruturalmente uniformes e têm relativamente poucas espécies. A vegetação de deserto é menos produtiva, mas a sua maior variedade estrutural aparentemente abre espaço para mais tipos de habitantes. A questão do porquê haver tantos tipos diferentes de árvores nos trópicos tem diversas respostas plausíveis. Estas podem ser agrupadas em cinco categorias, baseadas em heterogeneidade ambiental produzida por perturbações na estrutura uniforme da floresta, taxas de produção (por especiação ou imigração) de espécies competitivamente equivalentes, e o favorecimento de espécies raras por pressão consumidora.

\section{RELATO}

A heterogeneidade temporal imprevisível geralmente não é considerada como produtora da diversidade. Mas considerações teóricas sugerem que, dentro de certas circunstâncias, a variação de ano na taxa reprodutiva, tais como aquela que cada espécie predomina em alguns anos, pode conduzir à coexistência (SILVA et al., 2012). O mecanismo se baseia num tipo de dependência de frequência. Suponha que uma certa fração das árvores morra a cada ano e que cada uma seja substituída por um indivíduo da mesma espécie ou por um indivíduo de uma espécie diferente em proporção direta à produção de sementes de cada uma das espécies. Quando uma espécie é muito rara, um ano mau para a produção de sementes tem pouco efeito na probabilidade de estabelecimento de plântulas, mas um bom ano pode trazer uma comparável bonança - um pouco menos de quase nada é quase nada, mas um pouco mais representa um enorme aumento relativo. Analogamente, as espécies menos comuns obtêm uma vantagem relativa sobre as espécies mais comuns nos anos favoráveis a elas. Embora esse mecanismo possa funcionar na teoria, ele age fortemente somente sobre espécies muito raras. Qualquer grau de inferioridade competitiva 
rapidamente empurra uma espécie para a categoria de muito rara. Além disso, como todas as espécies devem experimentar alguns anos durante os quais elas produzem mais sementes do que todas as outras espécies, relativamente poucas espécies podem coexistir somente por este mecanismo. Este mecanismo tornou-se conhecido como a hipótese da loteria. A colonização por loteria reduz a exclusão competitiva à extinção acidental e pode contribuir por exemplo para a coexistência de grandes números de peixes nas comunidades de recifes tropicais. Outros observadores relacionaram a alta diversidade das florestas úmidas tropicais e dos recifes de coral com níveis intermediários de perturbação nas comunidades. A hipótese de perturbação intermediária considera que as perturbações causadas por condições físicas, predadores e outros fatores abrem espaço para a colonização e iniciam um ciclo de sucessão de espécies adaptadas a colonizar sítios perturbados. Com um nível moderado de perturbação, a comunidade torna-se um mosaico de partes de habitat em diferentes estágios de regeneração: as partes juntas contêm a variedade completa das espécies características da série de sucessão. Para esta hipótese explicar satisfatoriamente as diferenças de diversidade entre as regiões, em especial a magnitude do gradiente latitudinal da diversidade de espécies de árvores, deve haver diferenças comparáveis no nível de perturbação. As taxas de substituição de árvores individuais nas florestas (isto é, o inverso da duração de vida média) não diferem acentuadamente das áreas temperadas para as áreas tropicais.

\section{DISCUSSÃO}

A hipótese de pressão de pragas prediz que as plântulas devem estabelecer-se menos facilmente próximas aos adultos da mesma espécie (árvore-mãe) do que a uma certa distância. Os indivíduos adultos podem abrigar populações de herbívoros e patogenias especializadas que rapidamente infestam os descendentes próximos; ademais, como a maioria das sementes germina próximo ao seu progenitor, os herbívoros podem ser atraídos pela abundância de plântulas de lá, enquanto negligenciam as poucas que germinam a uma certa distância. A previsão de que o sucesso da germinação e do estabelecimento deve aumentar com a distância foi testada em diversos estudos, os quais produziram resultados variados, mas geralmente consistentes com essa ideia. Se as plântulas se estabelecem mais rapidamente numa distância maior do genitor ou outros adultos da mesma espécie, os indivíduos da mesma espécie deveriam estar bastante dispersados numa floresta em vez de aleatoriamente associados ou agrupados. Esta previsão pode ser testada mapeando-se os indivíduos de cada espécie e aplicando-se uma de várias ferramentas estatísticas usadas para testar graus de dispersão. A maioria dos estudos mostrou que muitas espécies de árvores, especialmente as mais comuns, possuem distribuições significativamente agrupadas. Esse resultado pesa contra uma grande regra da pressão de praga na estrutura da comunidade florestal, mas o grau de agrupamento é relativo, e os herbívoros e as patogenias podem causar uma maior dispersão de indivíduos maduros do que ocorreria de outra forma (SOUZA et al., 2011). É difícil imaginar que a redução da competição possa ser uma propriedade intrínseca de qualquer população. A seleção dependente da densidade tende a aumentar o tamanho da população. Contudo, se a variação na competição explicasse a variação na 
diversidade, as forças relativas de competição interespecífica e intraespecífica teriam que variar em sua influência sobre o patrimônio genético (pool) da população.

\section{CONSIDERAÇÕES FINAIS}

As diferenças nessas forças relativas podem ser interpretadas em termos da geometria das relações de nicho (ALMEIDA et al., 2013). Num espaço de nicho com poucas dimensões, cada população tem relativamente poucos vizinhos. Conforme o número de dimensões aumenta, o mesmo número de espécies pode agrupar-se diferentemente no espaço de nicho, aumentando o número de vizinhos e reduzindo a assimetria da competição. Essa variedade pode impedir que cada população individual se adapte para competir eficientemente com seus vizinhos nas comunidades de altas dimensões de nicho, impedindo o surgimento de dominantes competitivos. A alta dimensionalidade pode ocorrer em ambientes fisicamente aperfeiçoados, como os trópicos úmidos e as profundezas abissais dos oceanos; enquanto em ambientes mais agrestes uns poucos fatores físicos podem dominar o caráter do espaço do nicho estabelecendo um pequeno número de dimensões criticamente importantes. Outrossim, como os fatores biológicos geram muitas dimensões de nicho, a dimensionalidade do nicho pode aumentar conforme as comunidades biológicas se formam ao longo do tempo, intensificando ainda mais a sua capacidade de sustentar muitas espécies contra a tendência evolutiva da dominação por um pequeno número de espécies (ALMEIDA et al. 2019).

\section{REFERÊNCIAS}

ALMEIDA, J. R.; SILVA, C. E.; SILVA, C. V. V.; AGUIAR, L. A.; GARCIA, V. S.; SOUZA, C. P.; LENZ, E. R. S.; LINS, G. A.; ALMEIDA, S. M.. Multifatorialidade em saúde ambiental. Environmental Scientiae, v.1, p.26-47, 2019. DOI: https://doi.org/10.6008/CBPC2674-6492.2019.002.0002

ALMEIDA, J. R.; SILVA, C. E.; RODRIGUES, M. G.. Evaluation of the environmental impacts caused by deforestation in the hydric regimen of the metropolitan region of Petrópolis (RJ), Brazil. Engineering Sciences, v.1, p.14-21, 2013. DOI: https://doi.org/10.6008/ESS2318-3055.2013.001.0002
SILVA, C. E.; SOUZA, F. M. N.; AGUIAR, L. A.; ALMEIDA, J. R.. Análise de riscos como instrumento para sistemas de gestão ambiental. Revista Ibero-Americana de Ciências Ambientais, v.3, p.17-41, 2012. DOI: http://doi.org/10.6008/ESS2179- 6858.2012.001.0002

SOUZA, F. M. N.; SILVA, C. E.; AGUIAR, L. A.; ALMEIDA, J. R.. Proposta para utilização da simulação computacional em análise de risco, avaliação de desempenho e sistemas de gestão ambiental. Revista Ibero-Americana de Ciências Ambientais, v.2, p.39-63, 2011. DOI: https://doi.org/10.6008/ESS2179-6858.2011.002.0003

A CBPC - Companhia Brasileira de Produção Científica (CNPJ: 11.221.422/0001-03) detém os direitos materiais desta publicação. Os direitos referem-se à publicação do trabalho em qualquer parte do mundo, incluindo os direitos às renovações, expansões e disseminações da contribuição, bem como outros direitos subsidiários. Todos os trabalhos publicados eletronicamente poderão posteriormente ser publicados em coletâneas impressas sob coordenação da Sapientiae Publishing, da Companhia Brasileira de Produção Científica e seus parceiros autorizados. Os (as) autores (as) preservam os direitos autorais, mas não têm permissão para a publicação da contribuição em outro meio, impresso ou digital, em português ou em tradução. 